\title{
Prevalence of oral mucosal lesions in young seniors in the Wrocław region
}

\section{Występowanie chorób błony śluzowej jamy ustnej \\ u młodych seniorów rejonu Wrocławia}

\author{
Beata Głowacka ${ }^{B, D, F}$, Tomasz Konopka ${ }^{A-C, E, F}$ \\ Department of Periodontology, Faculty of Dentistry, Wroclaw Medical University, Poland \\ A - research concept and design; $\mathrm{B}$ - collection and/or assembly of data; $\mathrm{C}$ - data analysis and interpretation; \\ $D$ - writing the article; $E$ - critical revision of the article; $F$ - final approval of the article
}

\section{Address for correspondence \\ Tomasz Konopka}

E-mail: tomasz.konopka@umed.wroc.pl

\section{Funding sources}

None declared

Conflict of interest

None declared

Received on July 20, 2018

Reviewed on August 24, 2018

Accepted on October 4, 2018

Published online on December 31, 2018

Cite as

Głowacka B, Konopka T. Prevalence of oral mucosal lesions in young seniors in the Wroclaw region. Dent Med Probl. 2018;55(4):405-410. doi:10.17219/dmp/97310

DOI

10.17219/dmp/97310

Copyright

○ 2018 by Wroclaw Medical University

and Polish Dental Society

This is an article distributed under the terms of the Creative Commons Attribution Non-Commercial License (http://creativecommons.org/licenses/by-nc-nd/4.0/)

\begin{abstract}
Background. The morbidity of certain oral pathologies, for example denture-related stomatitis, burning mouth syndrome (BMS) and benign neoplasms is higher in the elderly. It is necessary to periodically assess the changes in the profile of the occurrence of these diseases and determine the dominant risk factors associated with their incidence.

Objectives. The aim of the study was to evaluate the prevalence of oral mucosal pathologies (in particular, potentially malignant and cancerous disorders) in a randomly selected population of 65-74-year-old residents of Wrocław and Oława, Poland.
\end{abstract}

Material and methods. A group of 1,600 persons aged 65-74 years, living in Wrockaw (a large city) and Oława (a small town) were randomly selected to participate in the study. 285 people from Wrocław and 102 from Oława were examined. In a clinical dental examination, the following parameters were assessed: the number of teeth; probing/pocket depth (PD) and clinical attachment level (CAL) for all the teeth at 4 measuring points (on this basis, periodontal diagnoses were made according to American recommendations - of the American Center for Disease Control and Prevention and the American Academy of Periodontology (CDC/AAP)); and the presence of prosthetic restorations and their quality. In the anamnestic study, variables concerning the socioeconomic status, systemic conditions (comorbidity of selected general diseases, nicotine addiction status, body mass) and selected behaviors promoting oral health were determined.

Results. The most common clinical changes in the oral mucosa were denture-related stomatitis (6.7\%), hemangiomas (5.9\%) and fibromas (4.1\%). Potentially malignant disorders and cancerous lesions were diagnosed in 59 persons (15.2\% of the respondents). One case of tongue cancer was diagnosed in an inhabitant of Oława.

Conclusions. More than $1 / 3$ of the examined persons were diagnosed with certain clinical, pathological oral mucosal lesions requiring treatment, of which nearly half were potentially malignant and cancerous. Poor tooth brushing efficiency was associated with a higher incidence of pre-cancerous and cancerous lesions in the oral cavity.

Key words: the elderly, oral mucosa diseases, potentially malignant disorders, cross-sectional epidemiological study

Słowa kluczowe: osoby starsze, choroby błony śluzowej jamy ustnej, zaburzenia potencjalnie złośliwe, przekrojowe badanie epidemiologiczne 


\section{Introduction}

Some oral mucosal lesions are characteristic of old age and do not require treatment. These include dislocated and enlarged sebaceous glands observed in the buccal mucosa, and dilated lingual veins on the ventral surface of the tongue. Most oral mucosal lesions in the elderly have a multifactorial etiology. This includes systemic conditions typical for this age group, such as systemic diseases and a large number of medicines taken, metabolic changes and nutritional deficiencies. Moreover, the condition of the oral mucosa is affected by local factors: mechanical irritation (habitual biting of the oral mucosa, irritation caused by the edge of an ill-fitting denture or dental filling), thermal irritation (related to food intake or smoking), biofilm on natural and artificial surfaces, qualitative or quantitative changes in the secreted saliva, nicotine addiction, and alcohol abuse. ${ }^{1-5}$

The most common oral mucosa diseases in the elderly include candidiasis, burning mouth syndrome (BMS), lichen planus, leukoplakia, traumatic lesions, recurrent aphthous stomatitis, and pigmented nevus. ${ }^{6-8}$ Rare pathologies include lesions occurring during the course of dermatoses, e.g., in pemphigoid and in benign (fibroma, papilloma, hemangioma) and malignant tumors (cancer of the oral mucosa). ${ }^{7,8}$

The GLOBOCAN (project of the International Agency for Research on Cancer) data of 2012 shows that in Poland, $53.1 \%$ of cases of oral cancer (including lips) regard people aged 65-74 years. Mortality rates linked with this disease also demonstrate a positive correlation with aging, and for the $65-74$ age group, it is $7.6 \%$ in women and $38.1 \%$ in men. ${ }^{8}$ Therefore, oncological prophylaxis is an extremely important aspect of geriatric patient health. Squamous cell carcinoma, which accounts for $90 \%$ of head and neck lesions, ${ }^{9}$ in the early stages of development does not often display obvious morphological changes, which may hinder its early diagnosis. Elderly patients are not always regularly examined by a dentist, especially if they do not have natural teeth. Focusing on the treatment of systemic diseases additionally contributes to the delay in making a diagnosis and commencing treatment. Screening tests conducted as part of oncological prophylaxis should include the assessment of the oral mucosa in geriatric patients. An early detection of malignant tumors or potentially malignant disorders with a high probability of cancer development gives a chance for a complete recovery.

An ailment often diagnosed in the elderly is xerostomia. Australian studies show that the hypofunction of salivary glands occurs in $22.1 \%$ and a subjective feeling of dry mouth in $22.5 \%$ of the elderly. ${ }^{10}$ The simultaneous presence of both abnormalities was found in $5.7 \%$ of subjects. ${ }^{10}$ In the elderly, sialopenia is most frequently the side effect of drugs like anticholinergics, antidepressants, diuretics, hypotensives, sedatives, myorelaxants, antihistamines, opioid analgesics, and non-steroidal antiinflammatory drugs. ${ }^{11-13}$ The reduction of salivary gland secretion may also be caused by the occurrence of endocrinopathy (diabetes, thyroid disease), autoimmune diseases (Sjögren's syndrome, rheumatoid arthritis, systemic lupus erythematosus, scleroderma), granulomatous diseases, and local causes (head and neck radiotherapy, salivary gland diseases). ${ }^{11,14,15}$ Xerostomia has certain effects on the emotional state of the elderly, leading to a low mood and depressive states. Both subjective and objective complaints associated with dry mouth reduce the quality of life of geriatric patients.

The incidence of oral mucosal lesions in the elderly should be periodically examined in order to define their risk factors, including dental iatrogeny. Therefore, one of the assumptions of the undertaken cross-sectional epidemiological study was to assess the prevalence of clinical oral pathologies (in particular, potentially malignant oral disorders and neoplasms) in the selected population of 65-74-year-old residents of Wrocław and Oława.

\section{Material and methods}

An epidemiological study was carried out to assess the population aged 65-74 years, living in a city (Wrocław, 638,000 inhabitants) and a small town (Oława, 33,000 inhabitants) in the province of Lower Silesia in southwest Poland.

At the Ministry of the Interior and Administration in Warsaw, a group of 1,600 people $(1,000$ and 600 for Wrocław and Oława, respectively) was selected in a twotier draw (sex and age, respectively), thus a group with the symmetrical structure of sex and age was formed. A letter of invitation to participate in a free examination of oral health was sent to all the randomly drawn people. Persons for whom a valid phone number was established were additionally notified by telephone.

The study was carried out at the Department of Periodontology of Wroclaw Medical University and in a private specialist dental clinic in Oława (Praktyka Prywatna, Dentyści Oława). Persons reporting to take part in the study signed the statement approved by the Bioethics Commission at Wroclaw Medical University (opinion No. KB-712/2017), thereby agreeing to participate in the study and on the processing of data obtained. The applied exclusion criteria were as follows: general contraindications (including bacterial endocarditis in the past) and local contraindications (including acute odontogenic infection).

In the period between June 25 and October 30, 2017, 387 people (136 men and 149 women from Wrocław, and 50 men and 52 women from Oława) were examined. The response rate for the research was $32.8 \%$ (35.6\% for the large city and $25.5 \%$ for the small town). 
Based on the interview conducted among patients who agreed to participate, the following information was obtained:

- place of residence (Wrocław or Oława);

- age;

- gender;

- education (elementary, secondary, higher);

- general diseases: cardiovascular diseases (conditions without an incident, for instance coronary heart disease, cardiac arrhythmias or thrombotic diseases, and with a previous incident - myocardial infarction or stroke), hypertension, diabetes, osteoporosis - with the pharmacological treatment of the declared disease taken as the diagnostic criterion;

- genetic load in the form of periodontitis in the history (a survey question whether family members like grandparents, parents or siblings had lost their teeth because of progressive mobility);

- body weight and height along with the body mass index (BMI) based on these measurements;

- nicotine addiction: non-smokers (people who had never smoked or had smoked fewer than 100 cigarettes throughout their lives), ex-smokers (people who used to smoke regularly, but had been free of addiction for at least a year at the time of the examination) and current smokers (people who had been smoking a minimum of 1 cigarette a day during the 6 months preceding the examination) - for this subgroup, the pack-year index was determined, being the product of multiplying the number of packs of cigarettes smoked per day by the number of years the person had smoked);

- oral health behaviors: average number of visits to a dental clinic during the previous 5 years (at least 2 visits a year were considered regular), frequency of brushing natural teeth or prostheses (brushing at least twice daily was considered regular), frequency of replacing a toothbrush per year (at least once every 3 months was considered regular brush replacement), daily additional cleaning of the interdental spaces with dental floss or a special brush (yes/no);

- forms of dental treatment funding: only in state-financed facilities, only in private facilities, or a mix of the two.

The clinical examination was performed in LED lighting, with the use of a dental mirror and the $\mathrm{Hu}$ Friedy PCPUNC 15 periodontal probe (Hu-Friedy, Chicago, USA). Pathological oral mucosal lesions were evaluated clinically. All the lesions were verified by a periodontologist with more than 20 years' diagnostic experience (TK). Congenital anomalies or lesions not requiring treatment, for instance dislocated sebaceous glands, linea alba or varicose veins of the tongue, were not recorded. The effectiveness of tooth brushing was also evaluated, on the basis of the presence of supragingival plaque on the vestibular and lingual surfaces of the teeth, and was expressed by the plaque index (PI) according to O'Leary et al. ${ }^{16}$ The value of $\mathrm{PI}<30 \%$ was assumed as the exponent of effective brushing and the value $>70 \%$ was an indication of ineffective tooth brushing. The probing/pocket depth (PD) and clinical attachment level (CAL) were also determined at 4 points around each tooth: distal-buccal, mesial-buccal, mid-buccal, and mid-lingual. On the basis of this examination, the periodontal health status was categorized according to the American Center for Disease Control and Prevention and the American Academy of Periodontology (CDC/AAP) classification by Eke et al. ${ }^{17}$ The presence, condition and usefulness of existing dental prostheses were also assessed. The permanent restorations were assessed in terms of their quality in the perigingival area, the reconstruction of occlusal points/planes, the absence of their interference with central and non-central occlusion, and the absence of mechanical damage. The removable dentures were assessed in terms of their adhesion to the prosthetic base, their retention and stabilization, as well as the restored occlusal height.

In the statistical analysis, the difference in the prevalence of a feature in the adopted groups was analyzed by the $\chi^{2}$ test. The value of $p \leq 0.05$ was considered statistically significant. The statistical analysis was carried out using Statistica 13.1 software (StatSoft, Inc., Tulsa, USA).

\section{Results}

In total, 26 types of diagnoses were made in 137 subjects (35.4\%), including 71 women (35.3\%) and 66 men $(35.3 \%)$. As Table 1 shows, most often - in as many as $6.7 \%$ of people - denture-related stomatitis occurred. Another large group of diagnoses included potentially malignant disorders (leukoplakia, lichen planus and pigmented nevus) and benign neoplasms (hemangioma, fibroma, papilloma, and epulis), which - along with 1 case of tongue cancer - accounted for the morbidity of these changes in as many as $15.2 \%$ of the subjects. The less frequent diagnoses were as follows: angular cheilitis (11), leukokeratosis (8), candidiasis (3), herpesvirus infection (3), and diagnoses confirmed only in women - BMS (3), xerostomia (3) and geographic tongue (3). In the residents of Oława, the most common was fibroma $(7.8 \%)$, and in men hemangioma $(8.1 \%)$. Table 2 presents the influence of selected factors on the incidence of the identified potentially neoplastic and neoplastic disorders. A significantly more frequent occurrence of this group of pathologies was found in the people with the worst efficiency of tooth brushing $(p=0.048)$. A more frequent occurrence of these changes in current nicotine addicts was not confirmed statistically, although the lesions were diagnosed in $20 \%$ of these people. 
Table 1. Occurrence of oral pathologies depending on place of residence and sex

\begin{tabular}{|c|c|c|c|c|c|}
\hline \multirow[b]{2}{*}{ Diagnosis } & \multirow{2}{*}{$\begin{array}{l}\text { Entire group } \\
\qquad(n=387)\end{array}$} & \multicolumn{2}{|c|}{ Place of residence } & \multicolumn{2}{|c|}{ Sex } \\
\hline & & $\begin{array}{l}\text { Wrocław } \\
(n=285)\end{array}$ & $\begin{array}{l}\text { Oława } \\
(n=102)\end{array}$ & $\begin{array}{l}\text { women } \\
(n=201)\end{array}$ & $\begin{array}{c}\text { men } \\
(n=186)\end{array}$ \\
\hline Hemangioma & $23(5.9)$ & $17(6)$ & $6(5.9)$ & $8(4)$ & $15(8.1)$ \\
\hline Fibroma & $16(4.1)$ & $8(2.8)$ & $8(7.8)$ & $8(4)$ & $8(4.3)$ \\
\hline Leukokeratosis & $8(2.1)$ & $8(2.8)$ & 0 & $3(1.5)$ & $5(2.7)$ \\
\hline Leukoplakia & $7(1.8)$ & $4(1.4)$ & $3(2.9)$ & $3(1.5)$ & $4(2.2)$ \\
\hline Lichen planus & $6(1.6)$ & $6(2.1)$ & 0 & $5(2.5)$ & $1(0.5)$ \\
\hline Papilloma & $4(1)$ & $4(1.4)$ & 0 & $3(1.5)$ & $1(0.5)$ \\
\hline Candidiasis & $3(0.8)$ & $1(0.4)$ & $2(2)$ & $2(1)$ & $1(0.5)$ \\
\hline Geographic tongue & $3(0.8)$ & $1(0.4)$ & $2(2)$ & $3(1.5)$ & 0 \\
\hline BMS & $3(0.8)$ & $2(0.7)$ & $1(1)$ & $3(1.5)$ & 0 \\
\hline Xerostomia vera & $3(0.8)$ & $2(0.7)$ & $1(1)$ & $3(1.5)$ & 0 \\
\hline Recurrent aphthous stomatitis & $2(0.5)$ & $2(0.7)$ & 0 & $1(0.5)$ & $1(0.5)$ \\
\hline Smoker's palate & $2(0.5)$ & $2(0.7)$ & 0 & $1(0.5)$ & $1(0.5)$ \\
\hline Tongue cancer & $1(0.3)$ & 0 & $1(1)$ & 0 & $1(0.5)$ \\
\hline Epulis & $1(0.3)$ & $1(0.4)$ & 0 & $1(0.5)$ & 0 \\
\hline Other & $15(3.9)$ & $13(4.6)$ & $2(2)$ & $4(2)$ & $11(5.9)$ \\
\hline Total & $137(35.4)$ & $99(34.7)$ & 38 (37.3) & $71(35.3)$ & $66(35.5)$ \\
\hline
\end{tabular}

Data presented as number (percentage); BMS - burning mouth syndrome.

\section{Discussion}

Among the examined residents of Wrocław and Oława, clinical lesions of the oral mucosa requiring treatment were found in $35.4 \%$ of people. This was decidedly more compared to a regional study of young seniors from the province of West Pomerania (Poland), where they were observed in only $22.5 \%$ of people. ${ }^{18}$ The comparative study also noted the presence of lesions not requiring treatment, e.g., linea alba or dislocated sebaceous glands. Thus, the real difference between these studies in the incidence of treatment need for pathological changes on the mucous membrane was even greater. The inclusion of congenital abnormalities in the registered diagnoses, subjective complaints, for example xerostomia spuria, or not clearly defined, for example coated tongue, makes a comparative analysis very difficult. The most common diagnosis in our own study was denture-related stomatitis, observed in $6.7 \%$ of people. This is in line with the results of the Fifth German Oral Health Study (Fünfte Deutsche Mundgesundheitsstudie - DMS V) in young seniors, in which this diagnosis was made in $4.6 \%$ of people, significantly more often in the subjects with the lowest social status. ${ }^{19}$ In a regional cross-sectional Turkish study conducted in one of the districts of Istanbul in people over 65 years of age, denture-related stomatitis was the second, after varicose veins, pathology of the oral mucosa and occurred in $14.1 \%$ of the subjects. ${ }^{20}$ In a Polish nationwide study of people at this age, the most common diagnosis was leukoplakia with leukokeratosis, diagnosed in as many patients as $10.5 \%$, with a significant predominance in men. ${ }^{21}$ A comparison of the third and fifth German national studies shows a decrease in the prevalence of leukoplakia by $0.3 \%$ over a period of 17 years. ${ }^{19}$ This is related to the decline in the number of people addicted to tobacco, observed in recent decades. In our own observation, there were $16.5 \%$ of patients with nicotine addiction (leukoplakia in 1.8\%), in the province of West Pomerania there were $8.5 \%$ (leukoplakia in $1 \%$ ), ${ }^{18}$ and in Germany there were $10.7 \%$ (leukoplakia $0.7 \%$ ). ${ }^{19}$ The decrease in the prevalence of leukoplakia is related to the blurring of significant differences in the occurrence of this diagnosis in both sexes. In the assessment of the oral mucosa in young seniors from Lower Silesia, the rule regarding the more frequent incidence of lichen planus and BMS in women is confirmed, but from an epidemiological point of view, these differences were not spectacular. Also, the place of residence was not observed to influence in a particular way the incidence of oral mucosal lesions (with the exception of the more frequent incidence of leukokeratosis in a large city).

Diagnosing clinical oral mucosa pathologies in an epidemiological study sometimes can be difficult due to the inability to perform additional examinations (in particular, 
Table 2. Influence of the analyzed variables on the incidence of precancerous and cancer lesions (including tongue cancer, hemangioma, fibroma, papilloma, epulis, leukoplakia, lichen planus, and pigmented nevus in the oral mucosa) (59 lesions)

\begin{tabular}{|c|c|c|}
\hline Variable & Incidence & $p$-value \\
\hline $\begin{array}{l}\text { Place of residence } \\
\text { Wrocław } \\
\text { Oława }\end{array}$ & $\begin{array}{l}44(15.4) \\
15(14.7)\end{array}$ & 0.86 \\
\hline $\begin{array}{l}\text { Sex } \\
\text { female } \\
\text { male }\end{array}$ & $\begin{array}{l}34(16.9) \\
25(13.4)\end{array}$ & 0.34 \\
\hline $\begin{array}{l}\text { Smoking status } \\
\text { non-smoker } \\
\text { ex-smoker } \\
\text { current smoker }\end{array}$ & $\begin{array}{c}26(12.4) \\
20(17.8) \\
13(20)\end{array}$ & 0.12 \\
\hline $\begin{array}{l}\text { BMI } \\
\text { normal weight } \\
\text { overweight } \\
\text { obesity }\end{array}$ & $\begin{array}{l}17(15.9) \\
23(13.5) \\
19(17.4)\end{array}$ & 0.76 \\
\hline $\begin{array}{l}\text { Diabetes } \\
\text { yes } \\
\text { no }\end{array}$ & $\begin{array}{l}13(18.1) \\
46(14.6)\end{array}$ & 0.46 \\
\hline $\begin{array}{l}\text { Cardiovascular disease } \\
\text { yes } \\
\text { no }\end{array}$ & $\begin{array}{l}17(14.8) \\
42(15.4)\end{array}$ & 0.87 \\
\hline $\begin{array}{l}\text { Osteoporosis } \\
\text { yes } \\
\text { no }\end{array}$ & $\begin{array}{c}3(7) \\
56(16.3)\end{array}$ & 0.17 \\
\hline $\begin{array}{l}\text { Hypertension } \\
\text { yes } \\
\text { no }\end{array}$ & $\begin{array}{l}31(17.9) \\
28(13.1)\end{array}$ & 0.18 \\
\hline $\begin{array}{l}\text { Periodontitis } \\
\text { (defined by the CDC/AAP criteria) } \\
\text { yes } \\
\text { no }\end{array}$ & $\begin{array}{l}28(17.6) \\
25(14.5)\end{array}$ & 0.43 \\
\hline $\begin{array}{l}\text { Effectiveness of teeth brushing } \\
\mathrm{PI}<30 \% \\
\mathrm{PI}>70 \%\end{array}$ & $\begin{array}{l}10(10) \\
20(20)\end{array}$ & $0.048^{*}$ \\
\hline $\begin{array}{l}\text { Dental appointments } \\
\text { regularly } \\
\text { irregularly }\end{array}$ & $\begin{array}{l}26(21.3) \\
33(12.9)\end{array}$ & 0.052 \\
\hline $\begin{array}{l}\text { Tooth brushing } \\
\text { regularly } \\
\text { irregularly }\end{array}$ & $\begin{array}{l}45(16.5) \\
14(12.3)\end{array}$ & 0.29 \\
\hline $\begin{array}{l}\text { Cleaning of interdental spaces } \\
\text { yes } \\
\text { no }\end{array}$ & $\begin{array}{l}10(13.7) \\
43(16.6)\end{array}$ & 0.55 \\
\hline $\begin{array}{l}\text { Prosthetic treatment } \\
\text { correct } \\
\text { incorrect }\end{array}$ & $\begin{array}{c}18(14) \\
33(17.4)\end{array}$ & 0.41 \\
\hline $\begin{array}{l}\text { Form of dental treatment funding } \\
\text { state-financed (National Health Fund) } \\
\text { private } \\
\text { mixed }\end{array}$ & $\begin{array}{c}20(15) \\
21(15.4) \\
18(15.3)\end{array}$ & 0.93 \\
\hline
\end{tabular}

Data presented as number (percentage); BMI - body mass index; CDC/AAP - the American Center for Disease Control and Prevention and the American Academy of Periodontology; PI - plaque index;

* statistical significance.

mycological and histopathological). However, in all the dubious cases, the diagnostic process was widened, because the subjects were treated at our facility.
In our own material, the group of most frequently occurring oral mucosa pathologies (15.2\% patients) comprised potentially malignant disorders (leukoplakia, lichen planus and pigmented nevus), as well as neoplasms (benign - hemangioma, fibroma, papilloma, and epulis, and also 1 case of tongue cancer). This observation strengthens the message about the need for continuous education among patients and primary care physicians in the field of cancer prevention, and proper diagnostic and treatment processes. Our analysis of the influence of selected general factors (nicotine addiction, BMI, diabetes, cardiovascular diseases, osteoporosis, hypertension), local factors (periodontitis, prosthetic treatment, efficient tooth brushing) and behavioral factors (related to oral cavity hygiene) did not indicate a significant relationship between these factors and the occurrence of the aforesaid group of disorders. The only exception was the significantly more frequent incidence of these pathologies in people ineffectively brushing their teeth (PI > 70\%). This could result from the relatively small size of the assessed proliferative lesion group (59 patients with such diagnoses) and the etiological heterogeneity of the lesions, e.g., viral in papillomas, traumatic in fibromas or nicotine in leukoplakia.

In many studies, the incidence of oral mucosal lesions is not assessed in random samples in cross-sectional or cohort studies, but is referred to people seeking treatment in a specialist center. ${ }^{5,7,22-24}$ In contrast to an epidemiological assessment, in a short observational study, the possibility of conducting additional tests significantly broadens the diagnostic possibilities. The morbidity of all deviations from the physiological state of the oral mucosa (including congenital abnormalities and disorders not requiring treatment) may then be very high, especially in the elderly, and reach even more than $90 \%$ in the age group over 70 years. ${ }^{22}$ The most frequent deviations from the physiological clinical picture of the oral mucosa in the elderly are varicose veins and fissured tongue, reported in more than $1 / 2$ and $1 / 3$ of the subjects, respectively. ${ }^{22}$ In turn, the most frequent pathologies requiring treatment in such observations were as follows: in Wrocław (Poland) - oral candidiasis in $25 \%$ of the examined patients, ${ }^{7}$ in Bangkok (Thailand) - traumatic ulceration in $15.6 \%$ of the respondents ${ }^{22}$ and in Talca (Chile) - fibroma in $10.8 \%$ of people aged over 60 years. ${ }^{24}$ Even among the elderly who seek treatment, benign soft tissue tumors (fibroma, hemangioma and pyogenic granuloma epulis) may be the most common group of diseases, reaching up to $29 \%$ of diagnoses. ${ }^{24}$ Of course, the exact verification of the diagnoses is possible only after a histopathological examination. A certain limitation in studying the incidence of oral mucosa diseases in random samples is the necessity of making only clinical diagnoses, which may be subject to error in some situations, for instance, in the differentiation of fibroma and papilloma, or leukoplakia and lichen planus located on the tongue. 


\section{Conclusions}

To sum up, attention should be paid to the high frequency and variety of pathological oral mucosal lesions in young seniors in the Wrocław area. A matter of particular concern is the high incidence of potentially malignant lesions and benign neoplastic lesions. Therefore, regular visits to the dentist's office are necessary, even for toothless patients, to seek clinical verification and specialist treatment as soon as possible.

\section{References}

1. Pai A, Deverashetty P. Changing trends in the oral mucosa geriatric population - an epidemiological study. J Ind Acad Geriatr. 2017;13:10-17.

2. Scully C. Oral \& Maxillofacial Medicine. The Basis of Diagnosis and Treatment. $3^{\text {rd }}$ ed. Edinburgh, UK: Churchill Livingstone Elsevier; 2013;10-20.

3. Kim SK, Allen ED. Structural and functional changes in salivary glands during aging. Microsc Res Tech. 1994;28:243-253.

4. Agnihotri R, Gaur S. Implications of tobacco smoking on the oral health of older adults. Geriatr Gerontol Int. 2014;14:526-540.

5. Knychalska-Karwan Z. Oral mucosal pathological lesions in 4,752 patients treated at the Department of Conservative Dentistry at Jagiellonian University in Kraków, Medical College in the years 1961-1998 [in Polish]. Magazyn Stomatol. 2004;14(3):10-14.

6. MacEntee MI, Glick N, Stolar E. Age, gender, dentures, and oral mucosal disorders. Oral Dis. 1998;4:32-36.

7. Konopka T, Mendak M. Prevalence of oral mucosal diseases in patients of specialist clinics in Wrocław in the years 1992-2003 [in Polish]. Dent Med Probl. 2004;41:717-725.

8. GLOBOCAN 2012: Estimated cancer incidence, mortality and prevalence worldwide in 2012. http://iarc.fr/Databases/larc-Cancerbases/GLOBOCAN-2012. Accessed July 10, 2018.

9. Vigneswaran N, Williams MD. Epidemiological trends in head and neck cancer and aids in diagnosis. Oral Maxillofac Surg Clin North Am. 2014;26:123-141.

10. Thomson WM, Chalmers JM, Spencer AJ, Ketabi M. The occurrence of xerostomia and salivary gland hypofunction in a population-based sample of older South Australians. Spec Care Dent. 1999;19:20-23.

11. Smidt D, Torpet LA, Nauntofte B, Heegaard KM, Pedersen AM. Associations between labial and whole salivary rates, systemic diseases and medications in a sample of older people. Community Dent Oral Epidemiol. 2010;38:422-435.

12. Shetty SR, Bhowmick S, Castelino R, Babu S. Drug induced xerostomia in elderly individuals: An institutional study. Contemp Clin Dent. 2012;3:173-175.

13. Chew ML, Mulsant BH, Pollock BG, et al. Anticholinergic activity of 107 medications commonly used by older adults. J Am Geriatr Soc. 2008;56:1333-1341.

14. Lopez-Pintor RM, Casanas E, Gonzalez-Serrano J, et al. Xerostomia, hyposalivation, and salivary flow in diabetes patients. J Diab Res. 2016;2016:4372852.

15. Acauan MD, Figueiredo MA, Cherubini K, Gomes AP, Salum FG. Radiotherapy-induced salivary dysfunction: Structural changes, pathogenetic mechanisms and therapies. Arch Oral Biol. 2015;60:1802-1810.

16. O'Leary TJ, Drake RB, Naylor JE. The plaque control record. J Periodontol. 1972;43:38.

17. Eke PI, Dye BA, Wei L, Thornton-Evans GO, Genco JR. Prevalence of periodontitis in adults in the United States: 2009 and 2010. J Dent Res. 2012;91:914-920.

18. Lipkiewicz M. Periodontal condition in 65-74-year-old persons in West Pomerania [in Polish]. PhD thesis. Pomeranian Medical University in Szczecin, Poland, 2016.

19. Hertrampf K. Disease and medical care prevalence in young seniors (65-74 years of age). Oral mucosa findings [in German]. In: Jordan AR, Micheelis W, eds. Fünfte Deutsche Mundgesundheitsstudie (DMS V). Koln, Germany: Deutscher Zahnärzte Verlag DÄV; 2016:359-362.
20. Mumcu G, Cimilli H, Sur H, Hayran O, Atalay T. Prevalence and distribution of oral lesions: A cross-sectional study in Turkey. Oral Dis. 2005;11:81-87.

21. Konopka T, Dembowska E, Pietruska M, Dymalski P, Górska R. Periodontal status and selected parameters of oral condition of Poles aged from 65 to 74 years [in Polish]. Przegl Epidemiol. 2015;69:643- 47.

22. Jainkittivong A, Aneksuk V, Langlais RP. Oral mucosal conditions in elderly dental patients. Oral Dis. 2002;8:218-223.

23. Cebeci AR, Gülşahi A, Kamburoğlu K, Orhan BK, Öztaş B. Prevalence and distribution of oral mucosal lesions in an adult Turkish population. Med Oral Patol Oral Cir Bucal. 2009;14:E272-277.

24. Rivera C, Droguett D, Arenas-Márquez MJ. Oral mucosal lesions in a Chilean elderly population: A retrospective study with a systemic review from thirteen countries. J Clin Exp Dent. 2017;9:e276-283. 